\title{
Relationship between an Interview-Based Health Promotion Program and Cardiovascular Risk Factors at Japanese Companies
}

\author{
Takashi Shimizu $^{1}$, Itsuko Horiguchi ${ }^{2}$, Tokiko KATO ${ }^{3}$ and Shoji NaGATA ${ }^{1}$ \\ ${ }^{1}$ Department of Mental Health, Institute of Industrial Ecological Sciences, University of Occupational and \\ Environmental Health, ${ }^{2}$ Department of Public Health, Juntendo University School of Medicine and ${ }^{3}$ Department \\ of Community Health Nursing, Tokyo Women's Medical University School of Nursing, Japan
}

\begin{abstract}
Relationship between an Interview-Based Health Promotion Program and Cardiovascular Risk Factors at Japanese Companies: Takashi ShImIzu, et al. Department of Mental Health, Institute of Industrial Ecological Sciences, University of Occupational and Environmental Health, JapanThe present study investigated the relationship between an interview-based health promotion program and cardiovascular risk factors at manufacturing companies. Excluding insufficient data and the workers who took medication prescribed by a physician in 1993, the subjects were six hundred and twenty-nine 18-55yr-old employees who had been working at two manufacturing companies in Kyushu from 1993 to 1997. The intervention company introduced an interview-based health promotion program from 1993. The program consisted of health measuring, group education, and health interviewing all employees to help with their behavioral change. We subdivided the subjects into younger (18-34-yr-old) and older (3555 -yr-old) groups. We defined changing degree $(\Delta)$ with (the following data in 1997) minus (the initial data in 1993). With agreement of the subject companies, we compared the $\Delta$ of each item, including body mass index (BMI), systolic blood pressure (SBP), diastolic blood pressure (DBP), serum total cholesterol (T-cho), serum aspartate aminotransaminase (AST), serum alanine aminotransferase (ALT), and serum gammaglutamyl transpeptidase (GGTP), in the intervention with that in the reference. BMI and SBP decreased significantly after the program in the under 35-yr-old intervention group. On the other hand, Tcho, AST, ALT, and GGTP decreased and HDL increased significantly after the program in the over
\end{abstract}

Received Aug 19, 2003; Accepted March 31, 2004

Correspondence to: T. Shimizu, Department of Mental Health, Institute of Industrial Ecological Sciences, University of Occupational and Environmental Health, 1-1 Iseigaoka, Yahatanishi-ku, Kitakyusyu-City, Fukuoka 807-8555, Japan (e-mail:t-shimiz@nifty.com) 34-yr-old intervention group. Our results showed that the worksite health promotion had the potential to improve cardiovascular risk factors of Japanese employees.

(J Occup Health 2004; 46: 205-212)

Key words: Health promotion, Health measuring, Group education, Health interview, Cardiovascular risk factors, Worksite

In 1988, the Ministry of Labor launched the Total Health Promotion Plan (THP) under the Industrial Safety and Health Law to prevent employees' lifestyle-related diseases such as hypertension, hyperlipidemia, cardiovascular diseases, and cerebrovascular ischemic diseases ${ }^{1)}$. THP consisted of five procedures: health measuring, exercise education, health education, psychological consultation, and nutrition education. Health measuring of all employees was carried out along with and the other forms of education were performed for employees with abnormalities detected by health measuring.

In 1996, the Industrial Safety and Health Law stated that occupational health professionals such as occupational physicians and occupational health nurses were to provide health education to the employees with abnormalities detected in annual health check-ups, in order to improve their lifestyles and health status and to prevent lifestyle-related diseases such as cardiovascular diseases and cerebrovascular ischemic diseases ${ }^{1)}$.

In other countries where worksite health promotion programs have been in existence for a longer period, there have been many studies which evaluated the effects on employees' health such as obesity, smoking, hypertension, and hyperlipidemia ${ }^{2-6}$. On the other hand, in Japan only several such studies have been conducted ${ }^{7-10)}$. The evaluation of Japanese worksite health promotion programs has grown increasingly important in recent years.

We studied the long-term effectiveness of an interview- 
based and multi-component worksite health promotion mainly on cardiovascular risk factors such as obesity, hypertension, and hyperlipidemia.

\section{Materials and Methods}

After excluding insufficient data $(n=246)$ and the workers who took medication prescribed by a physician in 1993 ( $n=63)$, the subjects were six hundred and twentynine 18-55-yr-old employees who had been working at two manufacturing companies in Kyushu from 1993 to 1997. We were able to follow up 310 workers ( 249 males and 61 females) in the intervention company and 319 workers (258 males and 61 females) in the reference company from 1993 to 1997. An interview-based and multi-component health promotion program was introduced only in the intervention company to prevent cardiovascular diseases. The intervention company was a manufacturing company with about five hundred employees in 1993. The reference company was also a manufacturing company with about four hundred employees in 1993 and located in the same area as the intervention company.

\section{Interventions}

The interview-based health promotion program consisted of three components: (1) health interview, (2) health measuring, and (3) group education about health behavior.

In the health interview, carried out within three months after the health check-up, an occupational health nurse interviewed the employees on their lifestyles and work- styles. To help change their behavior or attitude, the focus was on employee-centered approach frequently with open-ended questions frequently and employing less advise-giving. For example, the nurse asked an employee, "What do you think about the result of your health examination?", or "What do you think about selfcare in your lifestyle with reference to result of the health checkup?" The same occupational health nurse conducted the health interview during the period observed.

From 1993 to 1994 , the health interview was given to volunteers and employees with abnormalities that had been detected in annual health check-ups. The criteria for abnormality in health check-up data were as follows: 1) $\mathrm{BMI}>=25\left(\mathrm{~kg} / \mathrm{m}^{2}\right)$, 2) $\mathrm{SBP}>=140(\mathrm{mmHg})$ or $\mathrm{DBP}>=90$ (mmHg), 3) T-cho $>=220(\mathrm{mg} / \mathrm{d} l)$, 4) HDL $<40$ $(\mathrm{mg} / \mathrm{d} l), 5)$ AST $>=40(\mathrm{U} / l)$ or $\mathrm{ALT}>=45(\mathrm{U} / l)$ or GGTP $>=70(\mathrm{U} / l)$. From 1995, the health interview was extended to all employees in the company (Fig. 1). The same occupational health nurse interviewed the employees from 1993 to 1996.

Health measuring consisted of measuring circulatory function and motion function such as muscle strength, resilience, agility, and equilibrium ${ }^{1)}$. It was one component of the THP and it was given to all employees in the company from 1993 to 1995.

Group education on health behavior including exercise, nutrition, and stress management was given to volunteers for three ninety-minute sessions a year from 1993 to 1996. The participation rates of the group education were between $20 \%$ and $27 \%$ during the period, as shown in Fig. 1.

The intervention company

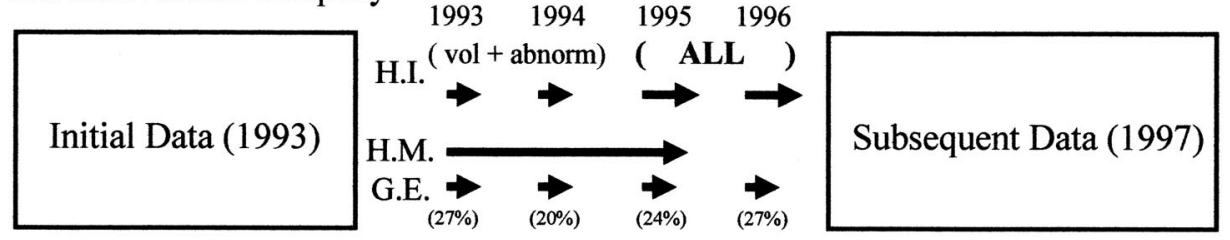

The reference company

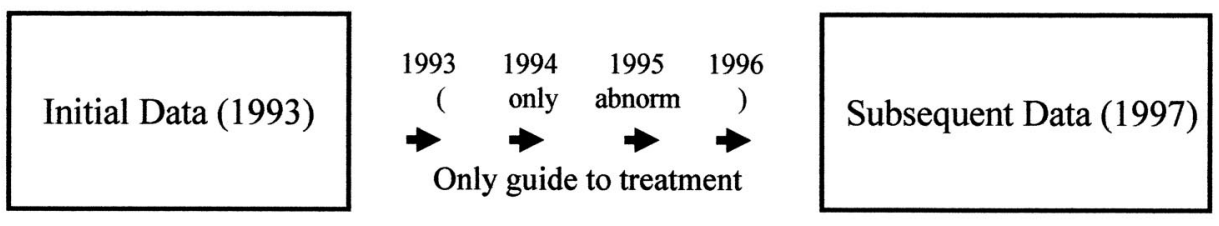

1) Vol : volunteers

2) Abnorm : employees with abnormalities in their annual health check-up results

3) H.I. : Health Interviews

4) H.M.: Health Measuring

5) G.E.: Group Education (Participation rate)

Fig. 1. The contents of the interview-based health promotion program 
On the other hand, in the reference company, an occupational health nurse guided a visit to medical institute for precise examination or drug treatment only for the employees with abnormalities. For example, the nurse would say to an employee, "You have hypertension detected in the health examination. Please visit a hospital and take medication prescribed by a physician." The criteria for the guidance were as follows: 1) $\mathrm{SBP}>=160(\mathrm{mmHg})$ or $\mathrm{DBP}>=95(\mathrm{mmHg}), 2) \mathrm{T}-\mathrm{cho}>=240(\mathrm{mg} / \mathrm{d} l), 3)$ AST $>=60(\mathrm{U} / l)$ or ALT $>=65(\mathrm{U} / l)$ or GGTP $>=90(\mathrm{U} / l)$. The same occupational health nurse guided the employees from 1993 to 1996.

\section{Data collection}

The Industrial Safety and Health Law states that employers must give all employees an annual health check-up, which includes a working and medical history, a physical examination, an audiogram, a visual acuity test, a blood pressure test, and a chest radiogram, and a blood and serum analysis and an electrocardiogram to employees aged 35 or more than $39^{1)}$.

The intervention company carried out a full examination, including a blood and serum analysis for all employees, but the reference company provided a full examination only for those employees aged 35 or over.

We collected health check-up data in 1993 and 1997 with the agreement of the subject companies, but noncomputerized data on employees' lifestyles were not collected during the observed period.

\section{Outcome measures}

For under 35-yr-old employees, we used body mass index (BMI), systolic blood pressure (SBP), and diastolic blood pressure (DBP) which were cardiovascular risk factors, as outcome measures.

For employees aged 35 or over, we employed BMI, SBP, DBP, serum total cholesterol (T-cho), and serum high density lipoprotein cholesterol (HDL) which are known as risk factors, as the measures. As additional measures, we used serum aspartate aminotransaminase (AST), serum alanine aminotransferase (ALT), and serum gammaglutamyl transpeptidase (GGTP) which were changed by alcohol consumption ${ }^{11-13)}$.

We defined the change in degree $(\Delta)$ with (the following data in 1997) minus (the initial data in 1993). We compared the $\Delta$ of each item in the intervention with that in the reference.

\section{Statistical Analysis}

We subdivided the subjects into younger (18-34 yr old) and older (35-55 yr old) group.

In each group, the data in the intervention in 1993 were compared with those in the reference in 1993 by the $t-$ test. We also compared the abnormality rate of BMI and blood pressure (BP) of the younger intervention group with those of the younger reference group by the chisquare test, and the abnormality rate of BMI, BP, T-cho, HDL, and liver function in the older intervention group with those in the older reference group by the chi-square test. We defined the abnormality rate as the percentage of workers who had need for education on a healthy lifestyle or consultation by a physician as a result of the health check-up data. The criteria for the abnormality rate were as follows: 1) $\left.\mathrm{BMI}>=25\left(\mathrm{~kg} / \mathrm{m}^{2}\right), 2\right) \mathrm{SBP}>=140$ $(\mathrm{mmHg})$ or $\mathrm{DBP}>=90(\mathrm{mmHg}), 3) \mathrm{T}-\mathrm{cho}>=220(\mathrm{mg} / \mathrm{d} l)$, 4) $\mathrm{HDL}<40(\mathrm{mg} / \mathrm{d} l), 5)$ AST $>=40(\mathrm{U} / l)$ or ALT $>=45(\mathrm{U} / l)$ or GGTP $>=70(\mathrm{U} / l)$.

In both the younger and older group, we subdivided the subjects into the non-treatment group, who took no medication from 1993 to 1997, and the treatment group, who took medication after 1993, and then, in the treatment group, the data for the intervention group in 1993 were compared with those of the reference group in 1993 by the t-test in order to ascertain the effect of drug treatment.

In the younger group, the $\Delta$ for each item in the intervention was compared with that in the reference by the analysis of covariance (ANCOVA) ${ }^{14}$, in which each $\Delta$ was adjusted by DBP because of a significant difference between the mean DBP in the intervention and that in the reference. In both the non-treatment group and the treatment group, we compared the $\Delta$ of each item for the intervention group with that for the reference group by the t-test to discuss the effect of drug treatment.

On the other hand, in the older group, that in the intervention was compared with that in the reference by the ANCOVA, in which each $\Delta$ was adjusted by age, Tcho, and HDL, because of statistical differences between mean age, T-cho, and HDL in the intervention and those in the reference. In both the non-treatment group and the treatment group, we also compared the $\Delta$ of each item in the intervention group with that in the reference group by the t-test to discuss the effect of drug treatment. AST, ALT or GGTP was natural-logarithmically changed into In_AST, In_ALT or In_GGTP, respectively, because of their skew distribution.

The calculations were performed with SPSS 10.0 J.

\section{Results}

Table 1 shows the characteristics of the younger subject in 1993. Only mean DBP in the intervention was significantly different from that in the reference. The abnormality rates of BMI and BP in the intervention were not different significantly from those in the reference. In the younger treatment group, there were no significant differences between mean BMI, SBP and DBP in the intervention and those in the reference.

On the other hand, in the older group, mean age, BMI, T-cho and HDL in the intervention were statistical different from those in the reference, although the abnormality rates of BMI, BP, T-cho, HDL and liver 
Table 1. Characteristics of the younger subjects in 1993

\begin{tabular}{|c|c|c|c|c|}
\hline & & Intervention & Reference & \\
\hline \multirow{3}{*}{ Percentage } & $\mathrm{n}$ & 110 & 160 & \\
\hline & Male & $80 \%$ & $86.3 \%$ & n.s. \\
\hline & Treatment & $7.3 \%$ & $6.3 \%$ & n.s. \\
\hline \multirow[t]{2}{*}{ Abnormality rate in 1993} & BMI & $17.3 \%$ & $15.6 \%$ & n.s. \\
\hline & Blood pressure & $7.3 \%$ & $8.8 \%$ & n.s. \\
\hline \multirow[t]{4}{*}{ Mean (SD) of total } & Age & $25.9 \quad(4.2)$ & $26.6 \quad(4.0)$ & n.s. \\
\hline & $\mathrm{BM}\left(\mathrm{kg} / \mathrm{m}^{2}\right)$ & $22.2(2.9)$ & $22.2 \quad(3.0)$ & n.s. \\
\hline & $\mathrm{SBP}(\mathrm{mmHg})$ & $121.0(14.3)$ & $121.3(14.6)$ & n.s. \\
\hline & $\mathrm{DBP}(\mathrm{mmHg})$ & $68.3(9.5)$ & $71.8(11.5)$ & $* *$ \\
\hline \multirow[t]{3}{*}{ Mean (SD) of treatment } & $\mathrm{BMI}\left(\mathrm{kg} / \mathrm{m}^{2}\right)$ & $22.3 \quad(2.9)$ & $21.7 \quad(2.9)$ & n.s. \\
\hline & $\mathrm{SBP}(\mathrm{mmHg})$ & $123.0 \quad(9.1)$ & $125.8(16.1)$ & n.s. \\
\hline & $\mathrm{DBP}(\mathrm{mmHg})$ & $73.8 \quad(8.2)$ & $78.6(13.4)$ & n.s. \\
\hline
\end{tabular}

1) Younger: 18-34 yr-old, 2) Treatment: Group took drug treatment after 1993, 3) n.s.: not significant by the chi-square test or ttest, 4) **: $p<.01,5)$ BMI: Body Mass Index, 6) SBP: Systolic blood pressure, 7) DBP: Diastolic blood pressure, 5) Abnormality rate of body weight $=\mathrm{BMI}>=25,6$ ) Abnormality rate of blood pressure $=\mathrm{SBP}>=140$ or $\mathrm{DBP}>=90$

Table 2. Characteristics of the older subjects in 1993

\begin{tabular}{|c|c|c|c|c|}
\hline & & Intervention & Reference & \\
\hline & $\mathrm{n}$ & 200 & 159 & \\
\hline \multirow[t]{2}{*}{ Percentage } & Male & $80.5 \%$ & $75.5 \%$ & n.s. \\
\hline & Treatment & $14 \%$ & $9.4 \%$ & n.s. \\
\hline \multirow[t]{5}{*}{ Abnormality rate } & BMI & $16.5 \%$ & $15.7 \%$ & n.s. \\
\hline & Blood pressure & $12 \%$ & $14.5 \%$ & n.s. \\
\hline & T-cho & $29.5 \%$ & $20.8 \%$ & n.s. \\
\hline & HDL & $15.5 \%$ & $10.7 \%$ & n.s. \\
\hline & Liver function & $17 \%$ & $13.8 \%$ & n.s. \\
\hline \multirow[t]{9}{*}{ Mean (SD) of total } & Age & $46.0 \quad(5.4)$ & $42.4 \quad(5.3)$ & $* * *$ \\
\hline & $\mathrm{BMI}\left(\mathrm{kg} / \mathrm{m}^{2}\right)$ & $22.7 \quad(2.6)$ & $22.2 \quad(2.8)$ & n.s. \\
\hline & $\mathrm{SBP}(\mathrm{mmHg})$ & $121.6(13.7)$ & $120.9(14.2)$ & n.s. \\
\hline & $\mathrm{DBP}(\mathrm{mmHg})$ & $75.7(10.5)$ & 75.9 (11.3) & n.s. \\
\hline & T-cho $(\mathrm{mg} / \mathrm{d} l)$ & $205.9(32.0)$ & $195.6(30.8)$ & $* *$ \\
\hline & $\mathrm{HDL}(\mathrm{mg} / \mathrm{d} l)$ & $53.5(13.4)$ & $55.7 \quad(14.3)$ & $\dagger$ \\
\hline & In_AST & $3.08(0.88)$ & $3.05 \quad(0.37)$ & n.s. \\
\hline & In_ALT & $3.04(0.60)$ & $3.04 \quad(0.55)$ & n.s. \\
\hline & In_GGTP & $3.09(0.88)$ & $3.15 \quad(0.69)$ & n.s. \\
\hline \multirow{8}{*}{ Mean (SD) of treatment } & BMI $\left(\mathrm{kg} / \mathrm{m}^{2}\right)$ & $22.6 \quad(2.6)$ & $23.6 \quad(3.2)$ & n.s. \\
\hline & $\mathrm{SBP}(\mathrm{mmHg})$ & $118.7 \quad(9.8)$ & 129.7 & $* *$ \\
\hline & $\mathrm{DBP}(\mathrm{mmHg})$ & $74.4 \quad(8.4)$ & 82.1 & $*$ \\
\hline & T-cho $(\mathrm{mg} / \mathrm{d} l)$ & $197.7(28.9)$ & 208.3 & n.s. \\
\hline & $\operatorname{HDL}(\mathrm{mg} / \mathrm{d} l)$ & $56.1(10.3)$ & 53.9 (16.8) & n.s. \\
\hline & In_AST & $3.09(0.28)$ & $3.31 \quad(0.76)$ & n.s. \\
\hline & In_ALT & $3.06(0.50)$ & $3.44 \quad(0.98)$ & n.s. \\
\hline & In_GGTP & $3.18(0.91)$ & $3.32(0.71)$ & n.s. \\
\hline
\end{tabular}

1) Older : 35-55 yr-old, Treatment : Group took drug treatment after 1993, 2) n.s. : not significant by the chi-square test or t-test, 3) **: $p<.01$ by the t-test, ***: $p<.001$ by the t-test, $\uparrow: p=.06$ by the t-testm, 4) BMI: Body Mass Index, SBP: Systolic blood pressure, DBP: Diastolic blood pressure, T-cho : serum total cholesterol, HDL : serum high density lipoprotein, AST : serum aspartate aminotransferase (U/l), ALT : serum alanine aminotransferase (U/l), GGTP : serum gammmaglutamyl transferase (U/l), 5) In_: natural-logarithmicalized, 6) Abnormality rate of body weight: $\mathrm{BMI}>=25,7$ ) Abnormality rate of blood pressure: $\mathrm{SBP}>=140$ or DBP $>=90,8)$ Abnormality rate of T-cho: T-cho $>=220$, 9) Abnormality rate of HDL: HDL<40, 10) Abnormality rate of liver function: AST $>=40, \operatorname{ALT}>=45$, or GGTP $>=70$ 
Table 3. Cardiovascular risk factors for the younger group before and after the interview-based health promotion

\begin{tabular}{|c|c|c|c|c|c|c|c|c|c|}
\hline \multirow[b]{3}{*}{$\Delta \mathrm{BMI}$} & \multirow[b]{3}{*}{ Intervention } & \multicolumn{2}{|c|}{ Non-treatment } & \multicolumn{3}{|c|}{ Treatment } & \multicolumn{3}{|c|}{ Total } \\
\hline & & \multirow{2}{*}{$\begin{array}{c}\mathrm{n} \\
102\end{array}$} & Mean (SD) & \multirow{2}{*}{$\begin{array}{c}\mathrm{n} \\
8\end{array}$} & \multicolumn{2}{|c|}{ Mean (SD) } & \multirow{2}{*}{$\begin{array}{l}\mathrm{n} \\
110\end{array}$} & \multicolumn{2}{|c|}{ Adjusted Mean (SE) } \\
\hline & & & $(1.2) * * *$ & & 0.9 & (1.7) & & 0.3 & $(0.1)^{* *}$ \\
\hline & Reference & 150 & $0.8 \quad(1.3)$ & 10 & 0.2 & $(1.7)$ & 160 & 0.8 & $(0.1)$ \\
\hline \multirow[t]{2}{*}{$\Delta \mathrm{SBP}$} & Intervention & 102 & $-5.1 \quad(10.4)^{* * *}$ & 8 & -3.4 & (7.6) & 110 & -5.7 & $(1.2)^{* * *}$ \\
\hline & Reference & 150 & $1.5 \quad(14.4)$ & 10 & -1.3 & $(17.6)$ & 160 & 1.8 & $(1.0)$ \\
\hline \multirow[t]{2}{*}{$\Delta \mathrm{DBP}$} & Intervention & 102 & $4.2 \quad(8.7)$ & 8 & 1.6 & (3.8) & 110 & 3.0 & $(0.9)$ \\
\hline & Reference & 150 & $2.0 \quad(12.4)$ & 10 & -2.7 & $(10.5)$ & 160 & 2.5 & $(0.8)$ \\
\hline
\end{tabular}

1) $\Delta=$ (the following data in 1997)—(the initial data in 1993), 2) Non-treatment: Group took no drug treatment after 1993 ,

3) Treatment: Group took drug treatment after 1993, 4)**: $p<.01, * * *: p<.001,5)$ adjusted : adjusted by DBP

Table 4. Cardiovascular risk factors for the older group before and after the interview-based health promotion

\begin{tabular}{|c|c|c|c|c|c|c|c|c|}
\hline & & & 1-treatment & & eatment & & Total & \\
\hline & & $\mathrm{n}$ & Mean (SD) & $\mathrm{n}$ & Mean (SD) & $\mathrm{n}$ & Adjusted & Mean (SE) \\
\hline$\Delta \mathrm{BMI}$ & Intervention & 172 & $-0.1 \quad(1.0)$ & 28 & $-0.1 \quad(1.0)$ & 200 & -0.07 & $(0.08)$ \\
\hline & Reference & 144 & $0.1 \quad(1.0)$ & 15 & $-0.6 \quad(1.5)$ & 159 & -0.03 & (0.09) \\
\hline$\Delta \mathrm{SBP}$ & Intervention & 172 & $0.7(12.2)$ & 28 & $3.5(11.6)^{*}$ & 200 & 1.1 & (1.0) \\
\hline & Reference & 144 & $-0.3(16.1)$ & 15 & $-5.9(11.0)$ & 159 & 0.7 & (1.1) \\
\hline$\triangle \mathrm{DBP}$ & Intervention & 172 & $1.2 \quad(8.2)$ & 28 & $2.1 \quad(9.0)$ & 200 & 1.4 & $(0.7)$ \\
\hline & Reference & 144 & $-0.2(10.4)$ & 15 & $-3.5(10.1)$ & 159 & -0.6 & $(0.8)$ \\
\hline$\Delta \mathrm{T}$-cho & Intervention & 172 & $-1.9(25.4)^{* * *}$ & 28 & $1.6(25.1)$ & 200 & -0.4 & $(1.7)^{* * *}$ \\
\hline & Reference & 144 & $14.7(23.3)$ & 15 & $13.1(25.9)$ & 159 & 12.8 & (1.9) \\
\hline$\Delta \mathrm{HDL}$ & Intervention & 172 & $5.3(10.9)^{* * *}$ & 28 & $6.5(11.3)$ & 200 & 5.3 & $(0.7)^{* * *}$ \\
\hline & Reference & 144 & $-0.2 \quad(7.7)$ & 15 & $1.8 \quad(7.3)$ & 159 & 0.2 & $(0.8)$ \\
\hline$\Delta \mathrm{In} \_\mathrm{AST}$ & Intervention & 172 & $-0.03(0.33)^{* * *}$ & 28 & $-0.09(0.28)$ & 200 & -0.04 & $(0.02)^{* *}$ \\
\hline & Reference & 144 & $0.09(0.27)$ & 15 & $-0.10(0.61)$ & 159 & 0.07 & $(0.03)$ \\
\hline$\Delta \mathrm{In} \_\mathrm{ALT}$ & Intervention & 172 & $-0.24(0.52)^{* * *}$ & 28 & $-0.32(0.36)$ & 200 & -0.25 & $(0.03)^{* * *}$ \\
\hline & Reference & 144 & $-0.01 \quad(0.39)$ & 15 & $-0.30(0.73)$ & 159 & -0.03 & $(0.04)$ \\
\hline$\Delta$ In_GGTP & Intervention & 172 & $-0.04(0.37)^{* * *}$ & 28 & $-0.16(0.37)$ & 200 & -0.06 & $(0.03)^{* * *}$ \\
\hline & Reference & 144 & $0.34(0.41)$ & 15 & $0.03(0.52)$ & 159 & 0.30 & $(0.03)$ \\
\hline
\end{tabular}

1) $\Delta=$ (the following data in 1997)-(the initial data in 1993), 2) Non-treatment: Group took no drug treatment after 1993, 3) Treatment: Group took drug treatment after 1993, 4) *: $\left.p<.05,{ }^{* *}: p<.01, * * *: p<.001,5\right)$ adjusted : adjusted by age, T-cho, and HDL

function in the intervention were not significantly different from those in the reference. The intervention group had higher age, higher BMI, higher T-cho and lower HDL than the reference group. In the older treatment group, the reference group had significantly higher SBP and DBP than the intervention group (Table 2).

In the younger group, $\triangle \mathrm{BMI}$ and $\triangle \mathrm{SBP}$ in the intervention were significantly lower those in the reference. $\triangle \mathrm{DBP}$ in the intervention did not change significantly, compared with that in the reference. In the non-treatment group, $\triangle \mathrm{BMI}$ and $\triangle \mathrm{SBP}$ in the intervention also were significantly lower than those in the reference, whereas, in the treatment group, there was no significant difference between $\Delta$ of each item in the intervention and those in the reference (Table 3).

Adjusted $\Delta \mathrm{T}$-cho, $\Delta \mathrm{In} \_\mathrm{AST}, \Delta \mathrm{In} \_\mathrm{ALT}$ and $\Delta \mathrm{In} \_\mathrm{GGTP}$ in the intervention were significantly lower than those in the reference. Adjusted $\triangle \mathrm{HDL}$ was significantly higher than that in the reference, but adjusted $\triangle \mathrm{BMI}, \triangle \mathrm{SBP}$ and $\triangle \mathrm{DBP}$ in the intervention were not changed significantly, compared with those in the reference. In the nontreatment group, $\Delta \mathrm{T}$-cho, $\Delta \mathrm{In} \_\mathrm{AST}, \Delta \mathrm{In} \_\mathrm{ALT}$ and $\Delta \mathrm{In} \_$GGTP in the intervention were significantly lower than those in the reference, but in the treatment group, $\triangle \mathrm{SBP}$ in the reference was significantly lower than that in the intervention (Table 4). 


\section{Discussion}

This study showed the long-term effectiveness of the interview-based and multi-component health promotion program for employees.

Our results showed that, in the intervention younger group, BMI was prevented from increasing and SBP decreased after the introduction of the program, compared with those in the reference. This result was compatible with the other studies, in which a multi-component worksite health promotion program improved cardiovascular risk factors such as BMI, BP, T-cho and triglycerides at Japanese worksites ${ }^{7,9)}$. This was considered reasonable because the health interview created in employees a readiness to change their behavior and the other programs further encouraged them do $\mathrm{so}^{15,16)}$.

We also found that, in the intervention older group, Tcho decreased and HDL increased significantly, compared those in the reference. The changes in T-cho and HDL corresponded to the previous study ${ }^{9)}$, in which T-cho and triglycerides decreased significantly and HDL was likely to increase after a multi-component worksite health promotion program. The improvement in T-cho and HDL would possibly occur due to changes in employees' behavior such as more physical activity and lower alcohol consumption after the program, as both are related to physical activity and alcohol consumption ${ }^{17-23)}$.

The improvement in AST, ALT and GGTP had the potential to decrease alcohol consumption in the intervention after the program's introduction because liver enzymes are related to alcohol consumption ${ }^{11-13)}$. This finding supported the improvement in T-cho and HDL through the employees' changed behavior.

We did not find a change in BMI or BP in the older group after the introduction. This finding was compatible with another study which showed that a program of exercise training decreased T-cho significantly but could not change $\mathrm{BMI}^{8)}$, and that $\mathrm{BMI}$ in middle-aged workers had a weak association with somatological factors ${ }^{24}$. In the treatment group, we found that mean SBP and DBP in the reference were significantly higher than those in the intervention, and that SBP and DBP in the reference decreased more significantly than in the intervention. These findings might indicate that BP was affected more strongly by drug treatment than by the program, but some studies showed an improvement in BMI and BP after worksite health promotion programs ${ }^{5,7)}$. Further study should investigate the long-term effectiveness of a worksite health promotion program on body weight and blood pressure through behavior in middle-aged and older workers.

Rollnick $^{10)}$ suggested that the limit to health promotion lay in the paradox that "a measure which brings large benefits to the community offers little to the participating individual" and it is important to understand that readiness to change beliefs or habits is usually the product of inner change combined with the external opportunity to consider practical alternatives at a time and pace appropriate to each person.

In the interview-based health promotion, an occupational health nurse interviewed all employees to help in changing belief and behavior, in other words, to make workers ready to change at a pace appropriate to each employee by using open-ended questions, which Rollnick indicated were more effective than advisegiving ${ }^{15)}$.

We believe that the critical keys to the success of the program were three factors. The first was the same occupational health nurse giving to all employees an interview helping to change employees' belief or behavior. Second, the program was supported by the superiors who encouraged their staff to participate in the program. Third, the employer permitted the occupational health nurse and the superiors to provide an interviewbased health promotion program. Other studies suggested that the critical keys to performing health promotion activities and improved health promotion were occupational health nurses and safety and health supervisors at Japanese worksites ${ }^{25,26)}$.

The barriers to implementation of worksite health promotion programs in small-scale enterprises were the lack of health personnel and budgetary restrictions ${ }^{27)}$, but this interview-based promotion program was actually performed in a small-scale company. The interview helping all employees to change their behavior was carried out by one occupational health nurse and it was a necessary component of the program. Our study may suggest the future direction of worksite health promotion programs in Japanese small-scale companies.

The present study had a non-randomized and quasiexperimental design. While the intervention company did not carry out exactly the same work as the reference company, both were of the same size and located in the same area, so we can reasonably conclude that they had similar organizational and financial characteristics and would have undergone similar economical and organizational changes in the period from 1993 to 1997.

The present study also had other limitations. We were unable to collect data on workers' lifestyles in the subject companies, and to completely remove the difference between a healthy worker effect ${ }^{28)}$ in the intervention company and that in the reference. Further study should investigate the effect of a worksite health promotion program, by using data including workers' lifestyles and considering the healthy worker effect on subject companies.

We were unable to remove a selection bias completely. The reference company had younger workers with significantly high DBP and the older workers with significantly higher age and T-cho than the intervention 
company. These findings might have the potential to underestimate the relationship between the interviewbased health promotion program and cardiovascular risk factors. Further study should investigate the relationship between them by adjusting for the effect of drug treatment.

The degree of change $(\Delta)$ employed as an outcome measure had a limitation. $\Delta$ was dependent on the initial value. We were unable to remove the effect of the initial data completely, although the initial value was adjusted by ANCOVA. Further study should measure the outcome of a health promotion program by matching the initial data in the intervention group with those in the reference group.

In conclusion, our results showed that an interviewbased health promotion program had the potential to have a favorable effect on cardiovascular risk factors for employees in a Japanese small-scale company. In the younger group, the program improved BMI and SBP. In the older group, it improved T-cho, HDL, AST, ALT and GGTP.

Acknowledgments: This study was supported by Keiko Takada and Kyoko Horikiri, occupational health nurses in the fields of this study. The authors are grateful for their cooperation. Appreciation is expressed to Prof. Marui, Dept. of Public Health, School of Medicine, Juntendo University, for valuable comments on this paper.

\section{References}

1) Ministry of Health, Labour and Welfare. General guidebook on industrial health 2001. Tokyo: Japan Safety and Health Association, 2002: 37-110.

2) R Bruno, C Arnold, L Jacobson, W Winick and E Wynder: Randomized controlled trial of a nonpharmacologic cholesterol reduction program at the worksite. Prev Med 12, 523-532 (1983)

3) KR Pelletier: A review and analysis of the health and cost-effective outcome studies of comprehensive health promotion and disease prevention programs at the worksite: 1993-1995 update. Am J Health Promot 10, 380-388 (1996)

4) MG Wilson: A comprehensive review of the effects of worksite health promotion on health-related outcomes: an update. Am J Health Promot 11, 107-108 (1996)

5) CA Heaney and RZ Goetzel: A review of health-related outcomes of multi-component worksite health promotion programs. Am J Health Promot 11, 290308 (1997)

6) S Ebrahim and GD Smith: Systematic review of randomized controlled trials of multiple risk factor interventions for preventing coronary heart disease. BMJ 314, 1666-1674 (1997)

7) K Furuki, S Honda, D Jahng, M Ikeda and T Okubo: The effects of a health promotion program on body mass index. J Occup Health 41, 19-26 (1999)

8) M Fukahori, H Aono, I Saito, T Ikebe and H Ozawa:
Programs of exercise training as total health promotion plan and its evaluation. J Occup Health 41, 76-82 (1999)

9) T Muto and K Yamauchi: Evaluation of a multicomponent workplace health promotion program conducted in Japan for improving employees' cardiovascular disease risk factors. Prev Med 33, 571577 (2001)

10) $Y$ Takata, $R$ Nakanishi, $C$ Isoda, $M$ Mino and $Y$ Maeda: The effect of a health promotion program at the worksite-An Approach to hyperlipoproteinemia in workers before middle age- - Jpn J Ind Health 45, 4349 (2003) (in Japanese with English abstract)

11) H Krinstenson, E Trell and B Hood: Serum- $\gamma$ glutamyltransferase in screening and continuous control of heavy drinking in middle-aged men. Am J Epidemiol 114, 862-872 (1981)

12) J Chick, N Kreitman and M Plant: Mean cell volume and gamma-glutamyl-transferase as markers of drinking in working men. Lancet 6, 1249-1251 (1981)

13) DH Lee, MH Ha and DC Christiani: Body weight, alcohol consumption and liver enzyme activity-a 4year follow-up study. Int J Epidemiol 30, 766-770 (2001)

14) Weinfurt KP. Repeated measures analyses: ANOVA, MANOVA, and HLM. In: Grimm LG, Yarnold PR eds. Reading and understanding more multivariate statistics. Washington, DC: American Psychological Association, 2002: 317-361.

15) S Rollnick, P Kinnersley and N Scott: Methods of helping patients with behavioral change. BMJ 307, 188-190 (1993)

16) N Scott, P Kinnersley and S Rollnick: The limits to health promotion. BMJ 309, 971-972 (1994)

17) E Barrett-Connor and L Suarez: A community study of alcohol and other factors associated with the distribution of high density lipoprotein cholesterol in older vs. younger men. Am J Epidemiol 115, 888-893 (1982)

18) K Misawa, H Matsuki, H Kasuga, H Yokohama and S Hinohara: An epidemiological study on the relationships among HDL-cholesterol, smoking and obesity. Jpn J Hyg 44, 725-732 (1989)

19) Oberman A, Riegelman RK, Weinsier RL, Pratt M, Benowitz NL and McLoughlin E. Principles of preventive health care. In: Bennett J C, Plum F, eds. Cecil textbook of medicine. 20th ed. Philadelphia: W. B. Saunders Company, 1996: 26-39.

20) Diamond I. Alcoholism and alcohol abuse. In: Bennett J C, Plum F, eds. Cecil textbook of medicine. 20th ed. Philadelphia: W. B. Saunders Company, 1996: 47-56.

21) T Ando, Y Shiraishi, M Sasaki, M Okuno, K Iijima, M Igarashi and E Kajii : Life-style and human dry dock: behavioral modification of exercise and diet habit. JMHTS 26, 376-384 (1999) (in Japanese)

22) N Nakanishi, M Okamoto, K Nishina, Y Matsuo, H Yoshida, K Shirai and K Tatara: Relationship between HDL and alcohol consumption in middle-aged male workers. Kosei no Shiryo 48, 15-21 (2001) (in Japanese) 
23) PA Metcalf, RK Scragg, BA Swinburn and LM Shaw: Factors associated changes in serum total cholesterol levels over 7 years in middle-aged New Zealand men and women: prospective study. Nutr Metab Cardiovasc Dis 11, 298-305 (2001)

24) Y Fukuda and M Futatsuka: Relationship between body weight and somatological factors by sex and age. J Occup Health 40, 16-21 (1998)

25) T Muto, M Tomita, S Kikuchi and T Watanabe: Methods to persuade higher management to invest in health promotion programmes in the workplace. Occup
Med 47, 210-216 (1997)

26) T Hirano, F Jitsunari, F Asakawa, S Suna, T Kitamado, I Fukunaga, N Takeda and H Kageyama: Impact of health professionals on health promotion activities in Japanese worksites. J Occup Health 42, 96-104 (2000)

27) T Muto, SD Hsieh and Y Sakurai: Status of health promotion programme implementation in small-scale enterprises in Japan. Occup Med 49, 65-70 (1999)

28) J Baillargeon and GS Wilkinson: Characteristics of the healthy survivor effect among male and female Hanford workers. Am J Ind Med 35, 343-347 (1999) 